THURSDAY, 15 JUNE TO SATURDAY, 17 JUNE 2017 Psychosocial support

\section{PARE0009 A TAXONOMY OF DISEASE EXPERIENCES OF WOMEN WITH SJÖGREN'S SYNDROME FROM THE PERSPECTIVE OF THE PATIENT}

M.Y. Visser-Noordegraaf ${ }^{1}$, V. Hiensch ${ }^{2}$, G. Rojas-Alcayaga ${ }^{3}$, R. Geenen ${ }^{2}$. ${ }^{1}$ NVSP, National Association Sjögren Patiënts, Maarssen; ${ }^{2}$ Psychology, Utrecht University, Utrecht, Netherlands; ${ }^{3}$ Faculty of Dentistry, Universidad de Chile, Santiago, Chile

Background: In earlier studies of experiences of patients with Sjögren's Syndrome (SS), professionals interpreted the data and drew conclusions and implications. In the current study, patients had a major share in the interpretation and structuring of experiences, and a patient research partner was part of the research group in all phases of the study: planning, collecting data, organizing, analyzing, and reporting.

Objectives: The aim of this study was to examine the full spectrum of life experiences of women with SS in an integrated, hierarchical model, and to examine the degree to which the research participants experienced the sorted experiences themselves.

Methods: Patients structured and interpreted the data using a concept mapping technique. In a card-sorting task, 52 patients with SS from the Netherlands grouped 75 experiences in piles. These experiences came from previous in-depth interviews with Chilean patients [1]. Hierarchical cluster analysis yielded an integrated, hierarchical model of these sortings. The 52 patients indicated on a 4-point Likert scale whether they had had these experiences themselves: agree, agree a little, disagree a little, disagree.

Results: Hierarchical cluster analyses showed a main 6-category clustering of experiences with primary symptoms, emotional processing, social interaction, self-management, ignorance, and physicians. Four of these categories showed underlying clusters of experiences (see Figure). Patients generally agreed to have common experiences of "primary symptoms", "role functioning barriers", and "diagnosis" and they commonly disagreed with the "psychologizing" symptoms, while they differed in the degree to which they had individually experienced the other experiences.

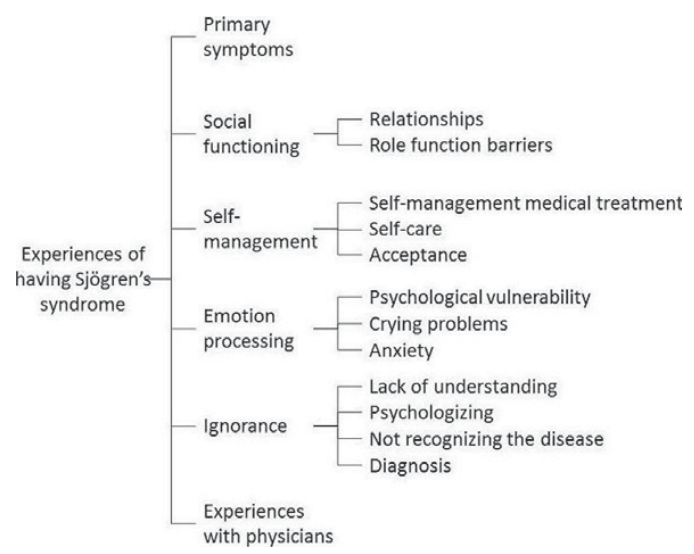

Conclusions: Life experiences of women with SS were summarized in an integrated, hierarchical model consisting of 14 clusters in 6 overarching categories. The results may be colored by the cultural background of the participants. This year this concept mapping study will be extended to patients from Chile, which will increase the generalizability of the findings and allow cross-cultural comparison. The final hierarchical overview with life experiences from the patient's view can be used to improve screening in clinical consults, develop a questionnaire, give direction to future research, and enhance education and self-management support [cf. 2]. The method gives ample room to really incorporate the patient perspective in research.

References:

[1] Rojas-Alcayaga $\mathrm{G}$ et al. Illness Experiences in women with oral dryness as a result of Sjögren's syndrome: The patient point of view. Musculoskeletal Care 2016;14: 233-42.

[2] Ammerlaan JW et al. Building a tailored, patient-guided, web-based selfmanagement intervention 'ReumaUitgedaagd!' for adults with a rheumatic disease. JMIR Res Protoc 2016:5:e113.

Disclosure of Interest: None declared

DOI: 10.1136/annrheumdis-2017-eular.2923
THURSDAY, 15 JUNE TO SATURDAY, 17 JUNE 2017 Arthritis research

\section{PARE0010 SIGNIFICANCE OF FOOT PROBLEMS FOR PATIENTS WITH RHEUMATOID ARTHRITIS: A PATIENT-LED QUALITATIVE STUDY}

S. de Souza, H. Lempp. Academic Rheumatology, King's College London, London, United Kingdom

Background: Patients with rheumatoid arthritis (RA) commonly report problems with their feet. ${ }^{1}$ It is known that foot joint involvement begins early in the course of RA and even patients on biologic therapy and/or with low disease activity can still experience high levels of foot pain. ${ }^{1-3}$ Current UK guidance states that "All people with RA and foot problems should have access to a podiatrist for assessment and periodic review of their foot health needs". ${ }^{4}$

Objectives: To understand how foot health problems affect patients with RA

Methods: Adult patients, with a diagnosis of rheumatoid arthritis and ability to converse in English, were recruited by clinicians based at a London hospital rheumatology outpatient clinic to participate in two focus groups on foot health. These were conducted by the lead patient researcher and comprised 8 females and 1 male of diverse ethnicities, aged 27-68 years old with 4-46 years disease duration. The focus groups were audio-recorded and transcribed verbatim. Transcripts were verified for authenticity by a random sample of 4 participants, and were systematically coded with the assistance of qualitative data analysis computer software. Themes were generated and cross-checked by the co-researcher to negate any potential bias by the lead patient researcher.

Results: Four interlinked themes were identified: 1) dependence on feet, e.g. needed for standing and walking; 2) physical impact e.g. pain, swelling and deformities; 3) social impact e.g. hard to keep appointments and participate in leisure activities; 4) psychological impact e.g. low self-esteem, worry and using humour to cope. The sole male participant was unaffected by theme 4 . One patient in the group had not experienced foot problems since diagnosis. No differences were identified across age, ethnicity or disease duration.

Conclusions: Foot problems can significantly lower quality of life for patients with RA. It is therefore essential that foot health is adequately addressed during rheumatology outpatient consultations with onward referral to podiatry services as necessary.

References:

[1] Grondal et al. The foot: still the most important reason for walking incapacity in rheumatoid arthritis: distribution of symptomatic joints in 1,000 RA patients. Acta Orthopaedica. 2008;79:257-61.

[2] Otter et al. Comparison of foot pain and foot care among rheumatoid arthritis patients taking and not taking anti-TNF $\alpha$ therapy: an epidemiological study. Rheumatol Int. 2011;31:1515-9.

[3] van der Leeden et al. Prevalence and course of forefoot impairments and walking disability in the first eight years of rheumatoid arthritis. Arthritis Rheum. 2008;59:1596-602.

[4] National Institute for Health and Care Excellence. Clinical Guideline 79, Rheumatoid arthritis: the management of rheumatoid arthritis in adults. 2009. Acknowledgements: We thank James Galloway and Carron Congreve for patient recruitment, Patience Duffort for transcription services and the patient participants for sharing their experiences.

Disclosure of Interest: None declared

DOI: 10.1136/annrheumdis-2017-eular.1400

\section{THURSDAY, 15 JUNE TO SATURDAY, 17 JUNE 2017 Best practice campaigning}

\section{PARE0011 ASK THE USERS - ESTABLISHING A DIGITAL USER PANEL \\ C.R. Ziegler ${ }^{1,2}$. ${ }^{1}$ Danish Rheumatism Association, Gentofte, Denmark; ${ }^{2}$ Policy and Research, Danish Rheumatism Association, Gentofte, Denmark}

Background: A high level of user involvement is one way of assuring campaigns to be relevant to people with RMD's. This is true for all projects within the PARE organisations. The Danish Rheumatism Association would like to strengthen our political campaigning and we found this goal could be reached by establishing a representative digital user panel. A representative digital user panel would give us quicker, more relevant and high quality information about the opinion of the users and their experience within many different aspects of living with RMD's in Denmark.

Objectives: The Danish Rheumatism Association wanted to strengthen the impact of our political campaigning. We wanted to establish a representative user panel consisting of 1500 Danes with RMD's. A digital user panel was found to be a quick and efficient tool to secure real life experiences and knowledge from the users. The user panel would make us interact with our users in even better ways and through that we were able to strengthen our political campaigning

Methods: In 2016 we tried to recruit participants among our members to assure that the panel was representative, but that was more difficult than we expected and we had to use other channels to recruit too. We wanted to ask the user panel about different themes 6-8 times each year. We investigated the collected data 
and used them directly in our political campaigning and communicative work without the time waster of making fancy reports.

Results: It turned out to be more difficult to establish a representative user panel than we thought. The barriers were various, but we succeeded in the end. The knowledge gained from the user panel has focused and strengthened our political work. This obtained influence would have been very difficult or even impossible to achieve without the experiences of the users. In our presentation we will go into details about the barriers of the establishing phase, share how we use the panel, give examples of how the answers are an added value and show how it helped us gain more political impact.

Conclusions: After overcoming several barriers it will possible to establish a digital user panel which can help organisations to improve their political campaigning.

Disclosure of Interest: None declared

DOI: 10.1136/annrheumdis-2017-eular.2824

\section{THURSDAY, 15 JUNE TO SATURDAY, 17 JUNE 2017 Patient information and education}

\section{PARE0012 EDUCATING YOUNG CHILDREN, PARENTS AND DOCTORS THROUGH THE MEDIUM OF AN ILLUSTRATED CHILDREN'S BOOK}

T. Egert ${ }^{1}$, Y. Egert ${ }^{2}$, R. Vitman ${ }^{1}$, W. Costello ${ }^{3} .{ }^{1} 4682$, Efrat, Israel; ${ }^{2}$ Netzach Yerushalayim 8, 4682, Efrat, Israel; ${ }^{3} 4682$, Dublin, Ireland

Background: Chronic illness in a child is a complex reality for all involved. The child often feels confused and afraid. He doesn't understand why he is sick and in pain, he worries about the doctor and hospital visits, as well as the medications and shots to which he is subjected. Parents are unsure how the illness will affect their child, and how to best prepare him for future challenges. Both parent and child are not always sure how to communicate to the Doctor their needs and concerns. Communication, however, between parent, doctor, child and health professional is critical for the effective treatment of the disease.

Objectives: This book attempts to open lines of communication between parent and child, to educate, give coping tools, and a voice to the young patient in a fun and optimistic manner. The book targets many of the children's challenges through identifying with Kipo, the young monkey who also has JIA.

The objectives: 1 . To give the child strength and tools to deal with his illness. 2 . Improve compliance through a better understanding of treatment.

Methods: A list of challenges young children with JIA face was compiled through meetings with parents, doctors and children. Next, a list of coping strategies was produced based on discussions with parents and health professionals. The story addresses the challenges and methods of dealing with them in a fun and optimistic manner through young Kipo's routine. Included are also messages addressed to the parent and doctor. To keep the child an active part of the story, thus allowing him to voice his concerns and discover coping skills, the story line requires active participation through "reading the pictures" which accompany the text. (The book includes a "how to read" guide). The back page includes a brief description of the illness, as well as other useful web addresses: parents associations, PRINTO, etc'. Results: Working jointly with the illustrator an illustrated children's book in 3 different languages (Hebrew, English and Arabic) was published. The book addresses the challenges and difficulties of a young child with JIA through the story of Kipo the monkey who is also ill. Included are a visit to the doctor, getting an injection, going to the physiotherapist, etc. The book is distributed free of charge though the paediatric rheumatologists to the families, and is received very enthusiastically by parents, children and doctors. The children read and reread the book sharing it with family, friends and kindergarten classrooms. They use the terminology introduced in the book to describe their own physical and emotional feelings, and adopt coping strategies used by Kipo.

Conclusions: The success of the book motivated us to allow for a more international distribution. The illustrations and the text are available allowing it to be used by any national group.

Acknowledgements: Inbar, Mifrakim Zeerim, ENCA, Dror Adam (illustrator), anonymous unaffiliated donors, doctors, parents and translators.

Disclosure of Interest: None declared

DOI: 10.1136/annrheumdis-2017-eular.1687

\section{PARE0013 BEHIND THE SMILE - RA AWARENESS VIDEOS - RAISING AWARENESS OF THE HIDDEN IMPACT OF RHEUMATOID ARTHRITIS}

\section{C.B. Jacklin, D. Saunders. External Affairs, National Rheumatoid Arthritis} Society, Maidenhead, United Kingdom

Background: NRAS was approached by Lilly Pharmaceuticals to contribute to the design and production of a series of videos to raise awareness of the hidden impact of rheumatoid arthritis. As this clearly met the charity's own objectives of raising awareness to a variety of audiences NRAS gladly collaborated on this project.

Objectives: The key aim of developing these resources to be utilised in European countries was to raise awareness of the impact of RA on daily life to 1) the general public, 2) clinicians, 3) payers, 4) industry and 5) people living with RA and their families. The challenge was to capture, in a two minute video, key messages that would resonate with all these stakeholders.

Methods: NRAS worked with a PR agency to develop an appropriate script for the main Behind the Smile resource. The main character, Jane, who lives with RA, was to be in her mid 30 s - to represent that RA is not associated with ageing; a school teacher - to represent that working is more than just a job for her and that she is a valued contributor to society; and a daughter, wife and mother - to represent how many other people depend on her and that she has commitments to.

We filmed with the support of Donna Saunders, NRAS Member \& Volunteer, on hand to comment and ensure authenticity of how the actress moved and dealt with every day activities. The final scene shows the character of Jane attending her clinic appointment with her rheumatologist and even then putting on a brave face and hiding behind the smile of the typical response "I'm fine".

In addition, Donna who lives with RA, was filmed giving her personal comments on the awareness film and insights into her personal struggles. Finally, Prof. lain Mclnnes, was filmed giving the clinicians perspective and offering advice as to how health care professionals need to keep at the forefront of their minds that patients are people and to be truly effective as physicians they should always make the time to open the dialogue on how the individual is truly "feeling"

Results: The films were released on World Arthritis Day 2016 via Lilly and NRAS social media channels in the UK. To date the "Jane" clip has been viewed in access of 200,000 times. The feedback from patients has been overwhelmingly that it has truly captured their "story". Physicians and industry staff have been left speechless and moved by the emotive film. NRAS and Lilly continue to utilise the films at health care professional training, staff and patient events.

Conclusions: Plans for 2017 is to develop more similar awareness raising videos as it is evident that using social media with video has impact and reach.

Acknowledgements: Acknowledge the support of Lilly Pharmaceuticals for the funding to develop these resources. The invaluable support of Prof.lain Mclnnes and patient Donna Saunders

Disclosure of Interest: C. Jacklin Grant/research support from: Lilly Pharmaceuticals, D. Saunders: None declared

DOI: 10.1136/annrheumdis-2017-eular.1909

\section{PARE0014 EXPLORING THE ADDED VALUE OF A BOOSTER SESSION AFTER COMPLETING THE DUTCH SELF-MANAGEMENT} TRAINING "CHALLENGING ARTHRITIS"

M. Vos ${ }^{1}$, R. Van den Brink ${ }^{2}$, S. de Jong ${ }^{2}$, J. Ammerlaan ${ }^{3} .{ }^{1}$ Expert Patient/Psychologist, Purmerend; ${ }^{2}$ Dutch Arthritis Foundation, Amsterdam; ${ }^{3}$ Rheumatology \& Clinical Immunology, University Medical Centre Utrecht, Utrecht, Netherlands

Background: In the Netherlands, the peer-guided self-management training "Challenging Arthritis" exists for over 15 years and is being organized by the Dutch Arthritis Foundation and the University Medical Center Utrecht. The training is based on the "Arthritis Self-Management Program"1 but has recently gone through several updates, improvements and extensions ${ }^{2}$. The goal of the training is to improve self-management skills of patients and thereby improving their physical and emotional health and quality of life. Evaluations show that participants highly appreciate the training, but some of them have suggested that they would like to have an extra moment of training, (i.e., a booster session) after the ending of the regular program. Research shows that self-management programs are effective but mostly in the short term ${ }^{3}$. The effects of "Challenging Arthritis" may be enhanced and prolonged by organizing booster sessions.

Objectives: Aim of this research is to make recommendations about organizing booster sessions based on 1) a literature search and 2) a needs assessment among former participants and peer trainers.

Methods: A literature search was performed in databases like Google Scholar, PubMed and Science Direct, focusing on articles about the use of boosters in self-management interventions, limited to the years 2000-2016. Next to that, a needs assessment was conducted among participants and trainers on needs and preferences, using two separate online surveys. The survey for the participants, who followed a live training between 2012 and 2015, included items on the need for a booster and on preferences regarding its form, content and frequency. The survey for peer trainers addressed the perceived usefulness and the trainers' willingness to provide booster sessions. The resulting data were analyzed using SPSS and thematic analysis.

Results: The literature search yielded 27 articles describing health interventions with aspects of self-management, including one or more booster sessions. From a theoretical perspective, boosters are a way to maintain new behavior over an extended period of time. As of yet, there is little evidence that the use of boosters lead to better outcomes in terms of health or health behavior, but it has been suggested that tailoring may lead to better results ${ }^{4,5}$. Regarding the needs assessment, 124 participants and 34 trainers completed the survey. Results showed that almost half of the participants (47,5\%) expressed a need for a booster, while the other half $(52,5 \%)$ expressed little or no need. Participants who prefer a booster want to share experiences, learn how to stay active with self-management and how to cope with setbacks. Trainers think boosters are very useful for the participants to stay active with self-management and maintain behavior and they are unanimously willing to provide booster sessions.

Conclusions: Boosters may contribute to the maintenance of newly acquired health behavior, although more research is needed on this subject. A substantial 